\title{
Non invasive ventilation as an additional tool for exercise training
}

\author{
Nicolino Ambrosino* and Paolo Cigni
}

\begin{abstract}
Recently, there has been increasing interest in the use of non invasive ventilation (NIV) to increase exercise capacity. In individuals with COPD, NIV during exercise reduces dyspnoea and increases exercise tolerance.

Different modalities of mechanical ventilation have been used non-invasively as a tool to increase exercise tolerance in COPD, heart failure and lung and thoracic restrictive diseases. Inspiratory support provides symptomatic benefit by unloading the ventilatory muscles, whereas Continuous Positive Airway Pressure (CPAP) counterbalances the intrinsic positive end-expiratory pressure in COPD patients.

Severe stable COPD patients undergoing home nocturnal NIV and daytime exercise training showed some benefits. Furthermore, it has been reported that in chronic hypercapnic COPD under long-term ventilatory support, NIV can also be administered during walking.

Despite these results, the role of NIV as a routine component of pulmonary rehabilitation is still to be defined.
\end{abstract}

Keywords: Chronic heart failure, COPD, Dyspnoea, Pulmonary rehabilitation

\section{Background}

During exercise in people with chronic obstructive pulmonary disease (COPD), expiratory flow limitation and increased respiratory frequency may reduce the expiratory time, resulting in increase in end-expiratory lung volume, a condition also known as dynamic hyperinflation (DH). In such condition, tidal breathing takes place at lung volumes closer to total lung capacity [1]. An unavoidable physiological consequence of $\mathrm{DH}$ is an increase in the intrinsic positive end-expiratory pressure (PEEPi) and in the elastic work of breathing (WOB): the final result is severe dyspnoea during effort reducing the exercise tolerance $[2,3]$.

Pulmonary rehabilitation is a recognised core component of the comprehensive management of COPD patients, mainly based on exercise training [4]. In patients with chronic heart failure (CHF), exercise training has beneficial direct and reflex sympatho-inhibitory effects and favorable effects on normalisation of neurohumoral excitation. These physiological benefits apply to all COPD and CHF patients independently of the degree of

\footnotetext{
* Correspondence: nico.ambrosino@gmail.com

Pulmonary Rehabilitation and Weaning Center, Auxilium Vitae, Borgo S. Lazzaro 5, Volterra, PI, Italy
}

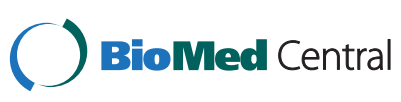

(C) 2015 Ambrosino and Cigni; licensee BioMed Central. This is an Open Access article distributed under the terms of the Creative Commons Attribution License (http://creativecommons.org/licenses/by/4.0), which permits unrestricted use, distribution, and reproduction in any medium, provided the original work is properly credited. The Creative Commons Public Domain Dedication waiver (http://creativecommons.org/publicdomain/zero/1.0/) applies to the data made available in this article, unless otherwise stated. disease severity and are associated with improved exercise tolerance, functional capacity, and quality of life [5].

Recently, there has been an increasing interest in the use of non invasive ventilation (NIV) to improve exercise capacity [6-8], based on the evidence that assisted ventilation, by unloading respiratory muscles, might allow patients to train at higher levels of exercise intensity. This review describes the present state of the art on the use of NIV as a tool to increase the benefits of pulmonary rehabilitation.

\section{Rationale}

In a study on healthy trained cyclists it was shown that the WOB required to sustain high-intensity exercise significantly inversely correlated with leg blood flow $[9,10]$. In other words, during leg exercise, in conditions like COPD where WOB increases, there may be a switch of blood flow from limb to respiratory muscles, thus inducing earlier limb muscle fatigue, a well known cause of exercise interruption. This competition may be minimised by adding assisted ventilation during exercise. Confirming this hypothesis, in other studies assisted ventilation prevented exercise-induced diaphragmatic fatigue $[11,12]$. Because PEEPi and less effective inspiratory muscles in COPD contribute to dyspnoea, assisted

racticle unless otherwise stated. 
ventilation should provide a symptomatic benefit by unloading and assisting the overburdened inspiratory muscles and reducing WOB. Unloading of the inspiratory muscles in turn may reduce their blood requirement allowing a switch of blood flow from respiratory to limb muscles.

Another aspect may be important. Systemic inflammation has been related to the development of comorbidities in COPD. The level of systemic inflammatory mediators is increased in response to exercise in these patients [13]. Non invasive ventilation may prevent the interleukin- 6 response to exercise in muscle-wasted COPD patients [14]. Furthermore, sympathetic and parasympathetic neural control of heart rate is deranged in COPD patients and NIV acutely increases sympathetic response and decreases vagal tonus: the increase in ventilation induced by NIV is associated with reduced cardiac vagal activity in stable moderate-to-severe COPD patients [15]. As a matter of fact, it has been claimed that NIV may be useful to improve exercise tolerance also in CHF [16].

Table 1 shows the suggested pathophysiological mechanisms of NIV effect during exercise.

\section{Physiological studies}

Different modalities of mechanical ventilation have been delivered non-invasively by nasal, facial Masks or mouthpiece during exercise [17].

\section{Continuous positive airway pressure}

Theoretically, CPAP should reduce the inspiratory threshold load on the inspiratory muscles of hyperinflated COPD patients and optimise neuromuscular coupling, thus improving dyspnoea and exercise tolerance [18-20]. CPAP counterbalances, at least in part, PEEPi (ie, the inspiratory threshold load) [21,22], reduces the WOB and increases exercise tolerance also in people with cystic fibrosis [23].

It has been suggested that the level of CPAP should be titrated on an individual basis to optimise benefit and comfort. Nevertheless, this implies the measurement of $\mathrm{PEEP} i$, which is difficult if not impossible to perform on

Table 1 Suggested pathophysiological mechanisms for the effect of NIV during exercise

\begin{tabular}{ll}
\hline Setting & Mechanism \\
\hline IPAP & WOB reduction \\
& Respiratory Muscle unloading \\
& Limb blood flow switch \\
& Anti inflammatory action \\
& Reduction in Vagal Tone \\
PEEP & Reduction in iPEEP \\
\hline
\end{tabular}

Abbreviations: IPAP, Inspiratory Positive Airway Pressure; PEEP, Positive End Expiratory Pressure; iPEEP, Intrinsic Positive End Expiratory Pressure; WOB: Work of Breathing. a routine basis [21]. CPAP seems also to be a useful strategy to improve functional capacity in patients with CHF, without any significant change in heart rate variability during physical exercises $[24,25]$.

\section{Inspiratory pressure support}

Inspiratory Pressure Support (IPS) is a pressure-targeted mode in which each breath is triggered and supported by the patient [26]. This modality of mechanical ventilation is able to assist ventilation effectively when applied non-invasively in acute and chronic respiratory failure. Pressure support can improve dyspnoea and exercise capacity by reducing the high WOB of exercising COPD patients [27-33]. Patients with severe COPD can sustain exercise-induced lactatemia longer if assisted by means of IPS [34]. Using near-infrared spectroscopy and impedance cardiography to assess changes in cerebral oxygenation and cardiac output, it has been found that non invasive IPS plus positive end expiratory pressure (PEEP) added benefit to hyperoxia during exercise in improving central haemodynamics and cerebral oxygenation in COPD patients with exercise induced desaturations [35]. It has been also reported that during the walking test on treadmill of cystic fibrosis patients, non invasive IPS may change thoraco-abdominal kinematics and lung function, improving exercise capacity suggesting that NIV may be an effective tool to increase functional capacity also in children and adolescents with cystic fibrosis [36]. Non invasive IPS has been used also to improve exercise tolerance in patients with restrictive ventilatory pattern $[37,38]$.

\section{Proportional assist ventilation}

Proportional Assist Ventilation (PAV) is a mode of partial ventilatory assistance endowed with characteristics of proportionality and adaptability to the intensity and timing of spontaneous ventilatory pattern by providing inspiratory flow and pressure in proportion to patient's effort [39]. PAV was proposed as a modality of mechanical ventilation to improve the patient-ventilator interaction by bringing one of the two oscillatory pumps, the mechanical ventilator, under the control of the other, the patient's central control of breathing [39]. Despite the positive characteristics, this modality of mechanical ventilation is still not used routinely in ICU. Several laboratory studies show that also non invasive PAV can increase exercise capacity of COPD patients without any relevant haemodynamic effect [40-44] in idiopathic pulmonary fibrosis (IPF) and obesity $[45,46]$.

In a comparison study [45] submaximal test was increased in IPF patients with PAV compared with CPAP and without any ventilatory support. IPF patients performing submaximal exercise with PAV presented a lower heart rate during exercise, although systolic and diastolic 
pressures were not different among submaximal tests. PAV applied during exercise led to increase in exercise endurance and reduction in dyspnoea also in obese patients [46]. In these patients there was a large spectrum of response to PAV, with more than $50 \%$ of patients increasing their exercise endurance by a mean of $31 \%$, thus suggesting that PAV might be a novel treatment option to enhance exercise capacity in a subgroup of obese patients in rehabilitation programs.

\section{Controlled mechanical ventilation}

Assist-control ventilation is a combination mode of ventilation in which the ventilator delivers a positive pressure breath at a preset tidal volume in response to a patient's inspiratory effort. The ventilator also delivers breaths at a preset rate if no patient effort occurs within the preselected time period [47]. This modality of assisted ventilation was delivered through nasal masks during exercise in patients with pulmonary tuberculosis sequelae and kyphoscoliosis, resulting in a significant improvement in breathlessness and increase in exercise endurance $[48,49]$. Its use was not studied in COPD patients.

\section{Non invasive ventilation in pulmonary rehabilitation programs}

The message of these physiologic studies can be summarised as follows: acute NIV, either as CPAP, IPS, or $\mathrm{PAV}$, during exercise reduces WOB and dyspnoea increasing exercise tolerance in COPD patients and with less level of evidence in restrictive disease patients [6]. The next step is to evaluate whether NIV can be used as an aid during exercise training sessions. This is an important issue, because most patients with moderate to severe COPD are candidates for pulmonary rehabilitation programs (PRP) [4], and PRP are component of the comprehensive management of majority of patients facing lung transplantation or lung volume reduction surgery [50,51].

One randomised controlled study [52] found no additional benefit from providing NIV (in PAV modality) during exercise training on bicycle, on exercise tolerance, dyspnoea, or health status when compared with training alone. At difference, another similar study [53] found that after a period of PAV-assisted training, mean training intensity, and peak work rate were higher than after unassisted training. Iso-workload lactataemia after training was reduced to a greater extent in the assisted than in unassisted patients. Moreover, a significant inverse relationship was found between reduction in isoworkload lactatemia after training during the constant work rate test and peak work rate achieved during the last week of training. This was considered as a marker of true physiologic training effect.

In another study COPD patients were randomised into three groups for an intervention of 12 weeks: exercise training alone, NIV alone and combined treatment. All exercise capacity parameters improved after training and the combined treatment. In addition, peripheral muscle strength and six-minute walk distance (6MWD) increased after NIV. Levels of interleukin 8 and tumour necrosis factor $\alpha$ decreased after ventilation, and interleukin 8, C-reactive protein and surfactant protein D decreased after training, while all four of these inflammatory markers fell after the combined treatment [54].

Other investigators have confirmed benefits of performing NIV during exercise training as a part of PRP [55-57].

There are some potential problems with the use of NIV in PRP:

1. Interface. During high-intensity exercise, some patients may breathe through their mouth rather than (or together with) their nose, therefore they may require a full-face mask or a mouthpiece. Full-face masks may be more uncomfortable than nasal masks, potentially reducing the patient's compliance to the procedure.

2. Comorbidities. Most of COPD patients have significant comorbidities, including a high prevalence of ischaemic cardiac disease [58]. The relief of exercise dyspnoea induced by with this kind of "mechanical doping" [59] might allow patients to exercise at a higher intensity and, as such, expose unaware ischaemic COPD patients to a load greater than their coronary ischemic threshold.

3. Practicalities. In the study [52], there was a high rate of drop-outs resulting from lack of compliance in the group under NIV. Furthermore, a mean 17-minute time spent to set the ventilator and supervise the training sessions with NIV was another practical drawback to the use of NIV during a high-intensity training program. It might not be practical or worthwhile to submit patients to unpleasant equipment (e.g., mask and related troubles), to the need for constant supervision of an individual operator to check for leaks and to reset the ventilator when needed and to a substantial risk for lack of patient compliance. The one-to-one patient therapist ratio increases the costs of the PRP. In these days of resource constraints this is a particularly important concern, especially comparing with the recognised benefits of well-conducted standard exercise training programs not requiring complex and sophisticated machinery or a personalised physiotherapist $[4,6,59]$.

\section{Night time NIV and day time exercise}

Severe stable COPD patients undergoing home nocturnal NIV and daytime exercise training showed a significant improvement in exercise capacity and health related 
quality of life compared with patients undergoing exercise training alone [60-62].

Furthermore, it has been reported that, in chronic hypercapnic COPD under long-term ventilatory support, NIV can also be administered during walking, resulting in improved oxygenation, decreased dyspnoea and increased walking distance. Therefore, NIV during walking could prevent hypoxia-induced complications [63,64].

Non invasive ventilation improves exercise tolerance in patients with acute exacerbations of chronic respiratory diseases, but the applicability of this approach in routine clinical practice may be limited $[65,66]$. In patients with restrictive disorders exercise training including NIV was shown to be feasible at home, whatever the modalities [67]. NIV alone is better than supplemental oxygen alone in promoting beneficial physiologic adaptations to physical exercise in patients with severe COPD [68]. Recently, wearable devices have been introduced to improve exercise tolerance of COPD patients [69].

\section{Conclusions}

Two recent meta-analyses concluded that, given the small number of available studies, the small sample sizes, and the complete absence of power calculation, there is the need of randomised clinical trials with larger sample sizes based on statistical power calculations and designed to investigate the effect of training duration and intensity on rehabilitation [70,71].

As application of NIV in rehabilitation programs is a demanding tool in terms of heath resources, there is the need to identify the best indications. Several questions remain open:

1. Who is the ideal candidate? Differences in results of different studies may be explained on the basis of different case mix, and apparently no study has directly addressed the topic of the best indication. Further studies are needed to identify the pathology (obstructive vs restrictive; hypoxaemic vs normoxaemic; hypercapnic vs normocapnic), the patient type, (naive to NIV vs acclimated to NIV; more vs less severely compromised patients).

2. Which are the most effective protocols? (e.g. training alone, vs nocturnal NIV, vs NIV under exercise).

3. Which are the most appropriate outcome indices to evaluate results? (e.g. tolerance to settings and equipments; incremental vs endurance test vs field test; Health Related Quality of Life vs dyspnoea vs daily life activities).

Despite promising results, for the above reasons and until the above questions are not answered, the authors of this review believe that the use of NIV during exercise training programs is unlikely to have a role in routine pulmonary rehabilitation settings. The use of NIV during exercise training as a component of PRP should be reserved to individual cases.

\section{Competing interests}

The authors declare that they have no competing interests.

\section{Authors' contributions}

Both authors read and approved the final manuscript.

\section{Acknowledgements}

None

Received: 16 January 2015 Accepted: 23 February 2015

Published online: 09 April 2015

\section{References}

1. O'Donnell DE, Revill SM, Webb KA. Dynamic hyperinflation and exercise intolerance in chronic obstructive pulmonary disease. Am J Respir Crit Care Med. 2001;164:770-7.

2. Babb TG, Viggiano R, Hurley B, Staats B, Rodarte JR. Effect of mild-to-moderate airflow limitation on exercise capacity. J Appl Physiol. 1991;70:223-30.

3. Marin JM, Carrizo SJ, Gascon M, Sanchez A, Gallego B, Celli BR. Inspiratory capacity, dynamic hyperinflation, breathlessness, and exercise performance during the 6-minute-walk test in chronic obstructive pulmonary disease. Am J Respir Crit Care Med. 2001;163:1395-9.

4. Spruit MA, Singh SJ, Garvey C, ZuWallack R, Nici L, Rochester C, et al. An official American Thoracic Society/European Respiratory Society statement: key concepts and advances in pulmonary rehabilitation. Am J Respir Crit Care Med. 2013;188:e13-64.

5. Vogiatzis I, Zakynthinos S. The physiological basis of rehabilitation in chronic heart and lung disease. J Appl Physiol. 2013;115:16-21.

6. Ambrosino N, Strambi S. New strategies to improve exercise tolerance in chronic obstructive pulmonary disease. Eur Respir J. 2004;24:313-22.

7. Ambrosino N, Guarracino F. Unusual applications of non-invasive ventilation. Eur Respir J. 2011:38:440-9.

8. Hill K, Holland AE. Strategies to enhance the benefits of exercise training in the respiratory patient. Clin Chest Med. 2014;35:323-36.

9. Harms CA, Babcock MA, McClaran SR, Pegelow DF, Nickele GA, Nelson WB, et al. Respiratory muscle work compromises leg blood flow during maximal exercise. J Appl Physiol. 1997:82:1573-83.

10. Harms CA, Wetter TJ, St Croix CM, Pegelow DF, Dempsey JA. Effects of respiratory muscle work on exercise performance. J Appl Physiol. 2000;89:131-8

11. Babcock MA, Pegelow DF, Harms CA, Dempsey JA. Effects of respiratory muscle unloading on exercise induced diaphragm fatigue. J Appl Physiol. 2002:93:201-6.

12. Borghi-Silva A, Oliveira CC, Carrascosa C, Maia J, Berton DC, Queiroga Jr F, et al. Respiratory muscle unloading improves leg muscle oxygenation during exercise in patients with COPD. Thorax. 2008:63:910-5.

13. Franssen FME, Rochester CL. Comorbidities in patients with COPD and pulmonary rehabilitation: do they matter? Eur Respir Rev. 2014;23:131-41.

14. Hannink JD, van Hees HW, Dekhuijzen PN, van Helvoort HA, Heijdra YF. Non-invasive ventilation abolishes the IL-6 response to exercise in muscle-wasted COPD patients: a pilot study. Scand J Med Sci Sports. 2014:24:136-43.

15. Borghi-Silva A, Silva Reis M, Goncalves Mendes R, Falasco Pantoni CB, Polaquini Simoes R, Barreto Martins LE, et al. Noninvasive ventilation acutely modifies heart rate variability in chronic obstructive pulmonary disease patients. Respir Med. 2008;102:1117-23.

16. Bündchen DC, Gonzáles Al, Noronha MD, Brüggemann AK, Sties SW, Carvalho TD. Noninvasive ventilation and exercise tolerance in heart failure: A systematic review and meta-analysis. Braz J Phys Ther. 2014;18:385-94.

17. Ambrosino N, Palmiero G, Strambi S. New approaches in pulmonary rehabilitation. Clin Chest Med. 2007;28:629-38.

18. O'Donnell DE, Sanii R, Younes M. Improvement in exercise endurance in patients with chronic airflow limitation using continuous positive airway pressure. Am Rev Respir Dis. 1988;138:1510-4.

19. O'Donnell DE, Sanii R, Giesbrecht G, Younes M. Effect of continuous positive airway pressure on respiratory sensation in patients with chronic obstructive 
pulmonary disease during submaximal exercise. Am Rev Respir Dis. 1988;138:1185-91.

20. Petrof BJ, Calderini E, Gottfried SB. Effect of CPAP on respiratory effort and dyspnoea during exercise in severe COPD. J Appl Physiol. 1990;69:179-88.

21. Rossi A, Polese G, Brandi G, Conti G. Intrinsic positive end-expiratory pressure (PEEPi). Intensive Care Med. 1995;21:522-36.

22. Lougheed MD, Webb KA, O'Donnell DE. Breathlessness during induced hyperinflation in asthma: role of the inspiratory threshold load. Am J Respir Crit Care Med. 1995;152:911-20.

23. Henke KG, Regnis JA, Bye PTP. Benefits of continuous positive airway pressure during exercise in cystic fibrosis and relationship to disease severity. Am Rev Respir Dis. 1993;148:1272-6.

24. Reis MS, Sampaio LM, Lacerda D, De Oliveira LV, Pereira GB, Pantoni CB, et al. Acute effects of different levels of contiuous positive airway pressure on cardiac autonomic modulation in chronic heart failure and chronic obstructive pulmonary disease. Arch Med Sci. 2010;6:719-27.

25. Reis HV, Borghi-Silva A, Catai AM, Reis MS. Impact of CPAP on physical exercise tolerance and sympathetic-vagal balance in patients with chronic heart failure. Braz J Phys Ther. 2014;18:218-27.

26. Brochard L. Pressure support ventilation. In: Tobin MJ, editor. Principles and practice of mechanical ventilation. 2nd ed. New York: McGraw-Hill inc; 2006. p. 221-50.

27. Keilty SE, Ponte J, Fleming TA, Moxham J. Effect of inspiratory pressure support on exercise tolerance and breathlessness in patients with severe stable chronic obstructive pulmonary disease. Thorax. 1994;49:990-6.

28. Wysocki M, Meshaka P, Richard JC, Similowsky T. Proportional-assist ventilation compared with pressure support ventilation during exercise in volunteers with external thoracic restriction. Crit Care Med. 2004:32:409-14.

29. Kyroussis D, Polkey Ml, Keilty SE, Mills GH, Hamnegard CH, Moxham J, et al. Exhaustive exercise slows inspiratory muscle relaxation rate in chronic obstructive pulmonary disease. Am J Respir Crit Care Med. 1996;153:787-93.

30. Polkey MI, Kyroussis D, Mills GH, Hamnegard CH, Keilty SE, Green M, et al. Inspiratory pressure support reduces slowing of inspiratory muscle relaxation rate during exhaustive treadmill walking in severe COPD. Am J Respir Crit Care Med. 1996;154:1146-50.

31. Maltais F, Reissmann H, Gottfried SB. Pressure support reduces inspiratory effort and dyspnea during exercise in chronic airflow obstruction. Am J Respir Crit Care Med. 1995;151:1027-33.

32. Kyroussis D, Polkey Ml, Hamnegard CH, Mills GH, Green M, Moxham J. Respiratory muscle activity in patients with COPD walking to exhaustion with and without pressure support. Eur Respir J. 2000;15:649-55.

33. van't Hul A, Gosselink R, Hollander P, Postmus P, Kwakkel G. Acute effects of inspiratory pressure support during exercise in patients with COPD. Eur Respir J. 2004;23:34-40.

34. Polkey MI, Hawkins P, Kyroussis D, Ellum SG, Sherwood R, Moxham J. Inspiratory pressure support prolongs exercise induced lactataemia in severe COPD. Thorax. 2000;55:547-9.

35. Rodrigues MK, Oliveira MF, Soares A, Treptow E, Neder JA. Additive effects of non-invasive ventilation to hyperoxia on cerebral oxygenation in COPD patients with exercise-related $\mathrm{O} 2$ desaturation. Clin Physiol Funct Imaging. 2013;33:274-81.

36. Lima CA, de Andrade AD, Campos SL, Brandão DC, Fregonezi G, Mourato IP, et al. Effects of noninvasive ventilation on treadmill 6-min walk distance and regional chest wall volumes in cystic fibrosis: Randomized controlled trial. Respir Med. 2014;108:1460-8.

37. Vila B, Servera E, Marín J, Díaz J, Giménez M, Komaroff E, et al. Noninvasive ventilatory assistance during exercise for patients with kyphoscoliosis: a pilot study. Am J Phys Med Rehabil. 2007;86:672-7.

38. Borel JC, Wuyam B, Chouri-Pontarollo N, Deschaux C, Levy P, Pépin JL. During exercise non-invasive ventilation in chronic restrictive respiratory failure. Respir Med. 2008;102:711-9.

39. Younes M. Proportional assist ventilation. In: Tobin MJ, editor. Principles and practice of mechanical ventilation. 2nd ed. New York: McGraw-Hill inc; 2006. p. 335-64.

40. Bianchi L, Foglio K, Pagani M, Vitacca M, Rossi A, Ambrosino N. Effects of proportional assist ventilation on exercise tolerance in COPD patients with chronic hypercapnia. Eur Respir J. 1998;11:422-7.

41. Dolmage TE, Goldstein RS. Proportional assist ventilation and exercise tolerance in subjects with COPD. Chest. 1997;111:948-54.

42. Hernandez P, Maltais F, Gursahaney A, Leblanc P, Gottfried SB. Proportional assist ventilation may improve exercise performance in severe chronic obstructive pulmonary disease. J Cardiopulm Rehabil. 2001;21:135-42.
43. Poggi R, Appendini L, Polese G, Colombo R, Donner CF, Rossi A. Noninvasive proportional assist ventilation and pressure support ventilation during arm elevation in patients with chronic respiratory failure. A preliminary, physiologic study. Respir Med. 2006;100:972-9.

44. Carrascossa CR, Oliveira CC, Borghi-Silva A, Ferreira EM, Maya J, Queiroga Jr $F$, et al. Haemodynamic effects of proportional assist ventilation during high intensity exercise in patients with chronic obstructive pulmonary disease. Respirology. 2010;15:1185-91.

45. Moderno EV, Yamaguti WP, Schettino GP, Kairalla RA, Martins MA, Carvalho $\mathrm{CR}$, et al. Effects of proportional assisted ventilation on exercise performance in idiopathic pulmonary fibrosis patients. Respir Med. 2010;104:134-41.

46. Dreher M, Kabitz HJ, Burgardt V, Walterspacher S, Windisch W. Proportional assist ventilation improves exercise capacity in patients with obesity. Respiration. 2010;80:106-11.

47. Mancebo J. Assist-control ventilation. In: Tobin MJ, editor. Principles and practice of mechanical ventilation. 2nd ed. New York: McGraw-Hill inc; 2006. p. 183-200.

48. Tsuboi T, Ohi M, Cjin K, Hirata H, Otsuka N, Kita H, et al. Ventilatory support during exercise in patients with pulmonary tuberculosis sequelae. Chest. 1997;112:1000-7.

49. Highcock MP, Smith IE, Shneerson JM. The effect of noninvasive intermittent positive-pressure ventilation during exercise in severe scoliosis. Chest. 2002;121:1555-60.

50. Make B. Pulmonary rehabilitation and lung volume reduction surgery. In: Donner CF, Ambrosino N, Goldstein RS, editors. Pulmonary Rehabilitation. London: Arnold Pub; 2005. p. 297-303.

51. Gay SE, Martinez FJ. Pulmonary rehabilitation and transplantation. In: Donner CF, Ambrosino N, Goldstein RS, editors. Pulmonary Rehabilitation. London: Arnold Pub; 2005. p. 304-11.

52. Bianchi L, Foglio K, Porta R, Baiardi R, Vitacca M, Ambrosino N. Lack of additional effect of adjunct of assisted ventilation to pulmonary rehabilitation in mild COPD patients. Respir Med. 2002;96:359-67.

53. Hawkins $\mathrm{P}$, Johnson LC, Nikoletou D, Hamnegård CH, Sherwood R, Polkey MI, et al. Proportional assist ventilation as an aid to exercise training in severe chronic obstructive pulmonary disease. Thorax. 2002:57:853-9.

54. Márquez-Martín E, Ruiz FO, Ramos PC, López-Campos JL, Azcona BV, Cortés EB. Randomized trial of non-invasive ventilation combined with exercise training in patients with chronic hypercapnic failure due to chronic obstructive pulmonary disease. Respir Med. 2014;108:1741-51.

55. Van t'Hul A, Gosselink R, Hollander P, Postmus P, Kwakkel G. Training with inspiratory pressure support in patients with severe COPD. Eur Respir J. 2006;27:65-72

56. Johnson JE, Gavin DJ, Adams-Dramiga S. Effects of training with heliox and noninvasive positive pressure ventilation on exercise ability in patients with severe COPD. Chest. 2002;122:464-72.

57. Costes F, Agresti A, Court-Fortune I, Roche F, Vergnon JM, Barthélémy JC. Noninvasive ventilation during exercise training improves exercise tolerance in patients with chronic obstructive pulmonary disease. J Cardiopulm Rehabil. 2003;23:307-13.

58. Divo M, Cote C, de Torres JP, Casanova C, Marin JM, Pinto-Plata V et al. Comorbidities and risk of mortality in patients with chronic obstructive pulmonary disease. Am J Respir Crit Care Med. 2012;186:155-61.

59. Ambrosino N. Assisted ventilation as an aid to exercise training: a mechanical doping? Eur Respir J. 2006;27:3-5.

60. Garrod R, Mikelsons C, Paul EA, Wedzicha JA. Randomized controlled trial of domiciliary non-invasive positive pressure ventilation and physical training in severe chronic obstructive pulmonary disease. Am J Respir Crit Care Med. 2000;162:1335-41.

61. Duiverman ML, Wempe JB, Bladder G, Jansen DF, Kerstjens HA, Zijlstra JG, et al. Nocturnal noninvasive ventilation in addition to rehabilitation in hypercapnic patients with COPD. Thorax. 2008;63:1052-7.

62. Duiverman ML, Wempe JB, Bladder G, Vonk JM, Zijlstra JG, HAM Kerstjens HAM, et al. Two-year home-based nocturnal noninvasive ventilation added to rehabilitation in chronic obstructive pulmonary disease patients: A randomized controlled trial. Respir Res. 2011;12:112.

63. Dreher $\mathrm{M}$, Storre $\mathrm{J}$, Windisch W. Noninvasive ventilation during walking in patients with severe COPD: a randomised cross-over trial. Eur Respir J. 2007;29:930-6.

64. Menadue C, Alison JA, Piper AJ, Flunt D, Ellis ER. Non-invasive ventilation during arm exercise and ground walking in patients with chronic hypercapnic respiratory failure. Respirology. 2009;14:251-9. 
65. Menadue C, Alison JA, Piper AJ, Flunt D, Ellis ER. Bilevel ventilation during exercise in acute on chronic respiratory failure: a preliminary study. Respir Med. 2010;104:219-27.

66. Dyer F, Flude L, Bazari F, Jolley C, Englebretsen C, Lai D, et al. Non-invasive ventilation (NIV) as an aid to rehabilitation in acute respiratory disease. BMC Pulm Med. 2011;11:58.

67. Borel JC, Verges S, Pepin JL, Vivodtzev I, Levy P, Wuyam B. Home exercise training with non-invasive ventilation in thoracic restrictive respiratory disorders: a randomised study. Respir Physiol Neurobiol. 2009;167:168-73.

68. Borghi-Silva A, Goncalves Mendes R, Toledo AC, Malosá Sampaio LM, da Silva TP, Kunikushita LN, et al. Adjuncts to physical training of patients with severe COPD: oxygen or noninvasive ventilation? Respir Care. 2010;55:885-94.

69. Porszasz J, Cao R, Morishige R, van Eykern LA, Stenzler A, Casaburi R. Physiologic effects of an ambulatory ventilation system in chronic obstructive pulmonary disease. Am J Respir Crit Care Med. 2013;188:334-42.

70. Ricci C, Terzoni S, Gaeta M, Sorgente A, Destrebecq A, Gigliotti F. Physical training and noninvasive ventilation in COPD patients: a meta-analysis. Respir Care. 2014:59:709-17.

71. Menadue C, Piper AJ, van't Hul AJ, Wong KK. Non-invasive ventilation during exercise training for people with chronic obstructive pulmonary disease. Cochrane Database Syst Rev. 2014;5:CD007714.

\section{Submit your next manuscript to BioMed Central and take full advantage of:}

- Convenient online submission

- Thorough peer review

- No space constraints or color figure charges

- Immediate publication on acceptance

- Inclusion in PubMed, CAS, Scopus and Google Scholar

- Research which is freely available for redistribution 